Article

\title{
Contacts between Natives and Migrants in Germany: Perceptions of the Native Population since 1980 and an Examination of the Contact Hypotheses
}

\author{
Bryan Bohrer ${ }^{1, *}$, Maria-Therese Friehs ${ }^{2}$, Peter Schmidt ${ }^{3}$ and Stefan Weick ${ }^{1}$ \\ ${ }^{1}$ GESIS-Leibniz Institute for the Social Sciences, 68159 Mannheim, Germany; E-Mails: bryan.bohrer@gesis.org (B.B.), \\ stefan.weick@gesis.org (S.W.) \\ 2 Institute of Psychology, Osnabrück University, 49074 Osnabrück, Germany; \\ E-Mail: mariatherese.friehs@uni-osnabrueck.de \\ ${ }^{3}$ Institute for Political Science, Justus Liebig University Gießen, 35394 Gießen, Germany; \\ E-Mail: peter.schmidt@sowi.uni-giessen.de \\ * Corresponding author
}

Submitted: 26 August 2019 | Accepted: 29 November 2019 | Published: 27 December 2019

\begin{abstract}
For decades, migration to Germany has been a relevant social phenomenon resulting in an increasing share of foreigners and Germans with migration background in the German populace. Additionally, since 2015, Germany has experienced a substantial increase in the immigration of people seeking refuge and asylum from civil war, economic and environmental catastrophes, and other adverse living conditions. These developments can be assumed to have led to an increase in intergroup contact between Germans and foreigners. We investigate this phenomenon in a multifaceted fashion by combining a social indicator and monitoring approach using repeated cross-sections over time with a new panel approach using a short-time panel to study causal relations. As a first step, we descriptively analyze the development of intergroup contact experiences of the German population with foreigners in various areas of life using data from the ALLBUS survey collected over 36 years between 1980 and 2016. Specifically, we detail the diverging contact experiences of participants with and without migration background as well as participants in the former Eastern and Western part of Germany. In a second step, based on Allport's intergroup contact theory that contact with outgroup members may improve attitudes towards these outgroups and other related findings, we examine the longitudinal processes between positive intergroup contact with foreigners and attitudes towards foreigners using four waves of the GESIS Panel collected over approximately one and a half years. We apply special rigor to these analyses by differentiating stable differences in intergroup contact experiences and attitudes between participants from within-person processes and discussing the implications of this differentiation.
\end{abstract}

\section{Keywords}

ALLBUS; foreigners; Germany; intergroup contact theory; migrant background; migration

Issue

This article is part of the issue "Immigration from the Migrants' Perspective" edited by Alice Ramos (Institute of Social Sciences, Portugal), Eldad Davidov (University of Cologne, Germany/University of Zurich, Switzerland), Peter Schmidt (University of Giessen, Germany), Marta Vilar Rosales (Institute of Social Sciences, Portugal) and Dina Maskileyson (University of Cologne, Germany).

(C) 2019 by the authors; licensee Cogitatio (Lisbon, Portugal). This article is licensed under a Creative Commons Attribution 4.0 International License (CC BY).

\section{Introduction}

Migration has been a constant topic of importance in the Federal Republic of Germany. With the onset of the 1950s, the influx of members of the German minority in other countries migrating back to Germany predominantly from Central and Eastern European countries began. This influx was comprised of descendants of emi- 
grated Germans that had preserved the German culture and language after the Second World War and had dealt with hindrances and displacement. From 1950 to 2017, more than 4.5 million of these ethnic Germans migrated back to Germany, the majority doing so between 1985 and 2004 (Göttsche, 2018).

Since 1955, immigrants labelled as guest workers came to Western Germany in increasing numbers and from different countries (Alba, Schmidt, \& Wasmer, 2003). For a long time, the official position of German governments had been that these guest workers would not stay in Germany permanently, as Germany was not regarded as an immigration country. Finally, in 2000, the law was changed and children born from non-German citizens became German by birth, but they had to decide at the age of 21 whether they wanted to hold the German citizenship or to hold the citizenship of the country of origin of their parents.

Due to the turbulent nature of countries with civil war, difficult economic situations, and vitriolic political circumstances, the number of displaced individuals heading to Europe in seek of refuge and asylum has risen dramatically since 2015 . With millions of refugees having sought refuge in countries like Turkey, Pakistan, Lebanon, Iran, Ethiopia, and Jordan (United Nations High Commissioner for Refugees, 2016)-and with no clear consensus being found among EU countries as to how to distribute the refugees fairly throughout Europethe German government decided on a short-term strategy to deal with this crisis by opening their borders in 2015. According to the Bundesamt für Migration und Flüchtlinge (Federal Office for Migration and Refugees; 2019a), as a consequence, well over a million refugees came to Germany in the following years after this landmark decision, mostly being greeted with a positive reception from the German populace. However, political parties such as the Alternative for Germany and the Christian Social Union in Bavaria came forward with warnings that such an influx of refugees threatened the safety of the Western lifestyle, particularly due to the increase in Muslims. This stance was furthered due to incidents such as the string of sexual assaults on New Year's Eve 2015-2016 in Cologne and terrorist attacks carried out by Islamic State terrorists disguised as refugees.

To make matters more complex, the integration of migrants in Germany has been a persistent societal challenge (Alba et al., 2003; Coenders \& Scheepers, 2008; Heath et al., 2019), being characterized through legal frameworks, the social climate (Green, Visintin, \& Sarrasin, 2018; Hadler \& Flesken, 2018), and the experience of the majority population with migrants and vice versa (Kühnel \& Leibold, 2000). However, one should not forget the role individual factors (e.g., demographic characteristics, prejudice, authoritarianism, social networks, racism) play in this process as well (Pfenning, 2019; Schmidt \& Weick, 2017; Sola, 2018). Nonetheless, integration remains a process that happens largely through the interactions of members of different groups, or the simple fact that Germans get into contact with migrants. Examining the effect of intergroup contact on attitudes towards the outgroup, as well as attitudes on contact, has a long tradition in the social sciences; however, the study into this could be improved with modern methodologies and a focus on how individuals with migrant backgrounds experience intergroup contact (if at all) with said groups.

Consequently, this article seeks to expand upon past research, which had used only cross-sectional data or shorttime panels with small samples, by first examining where persons with German citizenship with varying migrant backgrounds might experience intergroup contact with foreigners living in Germany, and by examining how much contact these individuals have had over a time period of 20 years with migrants in various areas of life. Furthermore, this article will also shed light on the dispositions of the German majority towards foreigners as a minority group and the perception of intergroup contact between them. For this analysis, time-series data from 1980-2016 exists that allows for the examination of long-term social change.

Additionally, we will use large-scale short-time panel data to examine the interrelations of intergroup contact experiences and outgroup attitudes. This investigation will be advanced through the use of a newly proposed random-intercept-cross-lagged panel model (RI-CLPM; Hamaker, Kuiper, \& Grasman, 2015), which allows for examining both the within-person effects and the between-person effects of intergroup contact and attitudes. Furthermore, it grants the opportunity for a comparison with the conventional CLPM to find differences between the models and their results.

In the following section, we first give a short overview of the theoretical state of the art and empirical research in this area. Then, in Study 1 (Section 3), we use data from the German General Social Survey (ALLBUS) from 1980 to 2016 to examine the major differentiations between East and West Germany, the German and immigrant population, time points, and domains of contacts (GESIS, 2019a). Subsequently, we present the methods and the design of Study 2 (Section 4) employing data from the GESIS Panel and the comparison of classical autoregressive cross-lagged models with the newly proposed randomintercept CLPM differentiating between-and withinperson effects. Finally, we summarize the results and present some conclusions.

\section{Theory and Empirical Research}

According to the contact hypothesis, association with individuals from other social groups tends to improve positions on, and respect for, said groups (Williams, 1947). Since its inception, the meaning of this hypothesis has been clarified by a number of works; in particular, Allport (1954) postulates that prejudice, when not deeply ingrained in the character structure, could be decreased through positive contacts between majority and minority groups. This hypothesis has been extensively supported by authors such as Pettigrew and Tropp (2006) 
through meta-analysis; however, previous studies have also found that positive attitudes can facilitate positive experiences (Mallett, Wilson, \& Gilbert, 2008; Wagner, Schmidt, \& Kauff, 2019).

As an extension of these hypotheses, the prejudice hypothesis holds that individuals with strong prejudice towards other groups attempt to avoid contact with said minority groups (Pettigrew, Tropp, Wagner, \& Christ, 2011). Such an outcome, however, does not account for extreme cases of prejudice that potentially lead to aggressive actions against minorities and migrants. As previous research has found, individuals with strong prejudices experience contact with minorities and migrants as negative and are therefore prone to perceive further experiences as negative in turn (Schmidt, Weick, \& Gloris, 2019).

With this focus on prejudice and contact, understanding the opinion of majority groups on minorities being present in their society becomes paramount. As previously studied in Germany, the perception of Germans towards the threat of migrants and minorities affecting culture and economy is particularly important when considering the evaluations that members of the majority group give foreigners (Schmidt \& Weick, 2017). This is furthered by the majority's considerations of how Germany should handle the influx of specific immigrant groups (Schmidt \& Weick, 2017). However, this focus examines the majority's contact with foreigners residing in Germany, but does not consider the intricacies of contacts with said foreigners among individuals with migrant backgrounds themselves. Since efforts have been made in previous research to examine the differences between Eastern and Western Germany with focus being placed on contact with migrants (see Jäckle \& König, 2018; Wagner, van Dick, Pettigrew, \& Christ, 2003), this article will examine this as well to include an extensive picture of migrant contact throughout Germany.

\section{Study 1}

\subsection{Data and Methods}

In our first study examining the descriptive statistics of the German population, data from the ALLBUS was used (GESIS, 2019a). ALLBUS is a repeated cross-sectional survey that is generally performed every two years (Koch \& Wasmer, 2004). For the purposes of this study, cumulative data from 1980-2016 was used to focus on questions regarding personal contact with specific migrant groups among those with both no migrant background and those that either were born outside of Germany or have direct relatives (e.g., parents or grandparents) that migrated to Germany. Comparisons of East and West Germany were also made.

\subsection{Variables}

In order to examine the experiences of respondents, questions were taken from the ALLBUS data that asked respondents about their personal contact with foreigners living in Germany, specifically with regard to which area of life these contacts occurred (family, workplace, neighborhood, and circle of friends/acquaintances). The questions asked "Do you have any personal contact with foreigners living in Germany? Specifically..." with the follow-up being "...in your own family or close family circle?," “...at work?," “...in your neighborhood?,” and “...among your other friends and acquaintances?" respectively. Further questions regarding the country of origin of the respondent, their parents, and their grandparents were used to create specific migrant background cohorts. Due to the "country of origin" questions having first been asked in 1996 and only every ten years thereafter, only the data from 1996, 2006, and 2016 was used when analyzing them. For the analysis of East and West differences, data was used starting from 1980 for West Germany and 1994 for East Germany.

The composition of the German population with regard to its immigration status can only be restrictedly captured with the available surveys, even though such surveys allow for a meaningful look into contact between Germans and migrants. The ALLBUS data consistently asked respondents whether or not they held a German citizenship. Other nationalities are sadly not represented well enough in the data to allow for separate analysis. Having said this, there are three ALLBUS surveysnamely those aforementioned surveys from 1996, 2006, and 2016-that included country of origin questions for the respondent, their parents, and their grandparents. With these questions it is then possible to analyze how the number of individuals with migration backgrounds has changed over this 20-year timespan and, in particular, how contact frequencies between Germans without migrant backgrounds and foreigners have developed as well.

\subsection{Results}

Table 1 highlights the proportion of respondents in the ALLBUS data with migrant backgrounds, whether being migrants themselves or being the children/grandchildren of migrants. Interestingly, the percentage of respondents with no migrant background, while higher for those with a German citizenship, decreased slowly between 1996 and 2006, but starkly dropped heading into the next decade $(62.1 \%$ to $55.3 \%$ for all respondents and $66.8 \%$ to $58.8 \%$ for German citizens between 2006 and 2016). This decrease was accompanied with a moderate drop in those with a migrant background themselves; however, this was also complemented with an increase in those with either parental or grandparental migrant backgrounds. In other words, roughly $45 \%$ of all respondents had some level of migrant background in 2016, while the same was true for only $41.2 \%$ of those with German citizenship. In both cases, the amount of individuals with some level of migrant background has increased by approximately $10 \%$ over the two decades. 
Table 1. Proportion of respondents in the ALLBUS data with German citizenship and immigration background (in percent). Source: GESIS (2019a).

\begin{tabular}{|c|c|c|c|}
\hline Respondents & 1996 & 2006 & 2016 \\
\hline & \multicolumn{3}{|c|}{ All respondents } \\
\hline All respondents with German citizenship & 92.9 & 92.3 & 92.9 \\
\hline Respondent with German citizenship (Western German States) & 91.3 & 90.9 & 91.9 \\
\hline \multirow[t]{2}{*}{ Respondent with German citizenship (Eastern German States) } & 99.7 & 98.4 & 97.6 \\
\hline & \multicolumn{3}{|c|}{ All respondents } \\
\hline Respondent born in Germany, no migrant background & 64.7 & 62.1 & 55.3 \\
\hline Respondent not born in Germany & 17.1 & 18.6 & 15.3 \\
\hline Parent(s) of respondent not born in Germany & 12.0 & 13.3 & 17.7 \\
\hline \multirow[t]{2}{*}{ Grandparent(s) of respondent not born in Germany } & 6.3 & 6.1 & 11.7 \\
\hline & \multicolumn{3}{|c|}{ Respondents with German citizenship } \\
\hline Respondent born in Germany, no migrant background & 69.1 & 66.8 & 58.8 \\
\hline Respondent not born in Germany & 11.4 & 12.3 & 9.9 \\
\hline Parent(s) of respondent not born in Germany & 12.8 & 14.3 & 18.8 \\
\hline Grandparent(s) of respondent not born in Germany & 6.7 & 6.6 & 12.5 \\
\hline
\end{tabular}

Notes: Database from ALLBUS 1980-2016 (cumulative; weighted): 1996-respondents with German citizenship = 3,304, respondents without $=189$; in 2006, respondents with German citizenship =3,193 respondents without = 210; in 2016, respondents with German citizenship $=3,271$, respondents without $=179$.

Drastic differences between the East and the West appear even six years after German reunification when nationality is considered. There was only an infinitesimal share $(0.3 \%)$ of respondents from the East German states that were not German citizens; this was due in part to the fact that immigration from other countries was rather rare in the former German Democratic Republic. Even in 2016, a considerably lower proportion of foreigners were to be found in the East compared to the West.

Table 2 highlights the personal contact respondents had with foreigners residing in Germany based on their own migrant background. Except for those who experienced contact with foreigners in the family and had grandparents with migrant backgrounds between 2006 and 2016, every other group showed an increase in personal contact with foreigners over time. This could be interpreted as evidence of the increasing prevalence of foreigners across all areas of life-which would be conceivable with the increase in the immigrant population in Germany (see Bundesamt für Migration und Flüchtlinge, 2019b) - but what is glaring is the contrast between those with migrant background and those without. In particular, and while not surprising, the 2016 data highlights that the respondents with migrant background had more contact with foreigners in their family than any other group ( $49.2 \%$ compared to $23.7 \%$ for no migrant background, $32.7 \%$ for parents, and $26 \%$ for grandparents). While not as exaggerated, this effect is also visible for neighborhood contacts $(57.4 \%$ for respondents with migrant background, $47.7 \%$ for parents, $51.4 \%$ for grandparents, and a meager $38 \%$ for those without migrant background). In both of these cases, these effects were shown to have developed over the past two decades, with the severity of the difference growing over time. However, this does not pertain to circle of friends/acquaintances, with all groups boasting percentages over $50 \%$. Workplace contact has also been on the rise with $52.7 \%$ of autochthonous German respondents having had contact and more than $50 \%$ for all other groups; this has steadily increased for those with migrant backgrounds and has exponentially increased for natives.

Table 3 focuses on the percentage of respondents in Eastern and Western Germany that had personal contact with foreigners over time. It is important to note that no data was collected in Eastern Germany before the reunification. At initial glance, the most striking finding here is that the frequency of personal contact in all four areas of life has substantially increased over time. There are, however, significant differences in overall contact with foreigners between East and West Germany. Through comprehensive inspection, with all four areas of life being considered, more than $80 \%$ of Western Germans and $60 \%$ of Eastern Germans had some contact with foreigners in 2016. As a means of comparison, these percentages were closer to $67 \%$ for West Germans and $25 \%$ for East Germans in 1994. This can partially be explained by the low numbers of immigrants in Eastern Germany, both historically and today. According to the Statistisches Bundesamt (Federal Statistical Office), when not including Berlin, only about $5.8 \%$ of foreigners residing in Germany live in the Eastern German States as of 2018 (self-calculated; see Statistisches Bundesamt, 2019). This was even more dramatic in 2005 , with only $3.6 \%$ of all foreigners residing in East Germany (self-calculated; see Statistisches Bundesamt, 2019).

Interestingly, contact in the workplace and among friends was shown to occur rather often, with just over $60 \%$ of West Germans and more than a third of East 
Table 2. Percentage of respondents that had personal contact with foreigners residing in Germany in various areas of life. Source: GESIS (2019a).

\begin{tabular}{|c|c|c|c|}
\hline Respondents & 1996 & 2006 & 2016 \\
\hline & \multicolumn{3}{|c|}{ Family } \\
\hline Respondent born in Germany, no migrant background & 14.7 & 21.2 & 23.7 \\
\hline Respondent not born in Germany & 24.9 & 46.4 & 49.2 \\
\hline Parent(s) of respondent not born in Germany & 18.8 & 29.3 & 32.7 \\
\hline \multirow[t]{2}{*}{ Grandparent(s) of respondent not born in Germany } & 17.0 & 29.4 & 26.0 \\
\hline & \multicolumn{3}{|c|}{ Workplace } \\
\hline Respondent born in Germany, no migrant background & 39.0 & 41.2 & 52.7 \\
\hline Respondent not born in Germany & 28.4 & 42.0 & 60.2 \\
\hline Parent(s) of respondent not born in Germany & 41.9 & 47.7 & 56.5 \\
\hline \multirow[t]{2}{*}{ Grandparent(s) of respondent not born in Germany } & 51.4 & 58.4 & 67.1 \\
\hline & \multicolumn{3}{|c|}{ Neighborhood } \\
\hline Respondent born in Germany, no migrant background & 30.2 & 35.3 & 43.3 \\
\hline Respondent not born in Germany & 29.1 & 47.1 & 57.4 \\
\hline Parent(s) of respondent not born in Germany & 32.3 & 40.9 & 47.7 \\
\hline \multirow[t]{2}{*}{ Grandparent(s) of respondent not born in Germany } & 40.4 & 43.4 & 51.4 \\
\hline & \multicolumn{3}{|c|}{ Circle of Friends and Acquaintances } \\
\hline Respondent born in Germany, no migrant background & 42.1 & 45.1 & 55.7 \\
\hline Respondent not born in Germany & 37.2 & 56.6 & 63.3 \\
\hline Parent(s) of respondent not born in Germany & 50.7 & 53.4 & 60.3 \\
\hline Grandparent(s) of respondent not born in Germany & 57.7 & 61.5 & 70.8 \\
\hline
\end{tabular}

Note: Database from ALLBUS 1980-2016 (cumulative; weighted).

Table 3. Personal contact with foreigners residing in Germany in various areas of life (in percent). Source: GESIS (2019a).

\begin{tabular}{|c|c|c|c|c|c|}
\hline Statistical Territory & Year & Family & Work & Neighborhood & Friends \\
\hline \multirow{12}{*}{ Western German States } & 1980 & 5.3 & 22.9 & 19.7 & 14.7 \\
\hline & 1984 & 6.3 & 25.5 & 22.5 & 22.3 \\
\hline & 1988 & 7.3 & 23.6 & 27.6 & 24.6 \\
\hline & 1990 & 10.9 & 34.4 & 27.6 & 31.2 \\
\hline & 1994 & 16.4 & 41.8 & 31.8 & 43.0 \\
\hline & 1996 & 19.1 & 45.4 & 37.2 & 50.8 \\
\hline & 2000 & 22.3 & 41.6 & 38.0 & 50.1 \\
\hline & 2002 & 29.2 & 52.9 & 43.3 & 60.8 \\
\hline & 2006 & 28.8 & 48.6 & 44.3 & 54.4 \\
\hline & 2010 & 27.4 & 51.0 & 46.4 & 57.8 \\
\hline & 2012 & 34.9 & 62.1 & 50.8 & 67.3 \\
\hline & 2016 & 31.1 & 60.7 & 52.3 & 64.7 \\
\hline \multirow{8}{*}{$\begin{array}{l}\text { Eastern German States } \\
\text { (Former East Germany) }\end{array}$} & 1994 & 4.6 & 12.7 & 4.4 & 12.9 \\
\hline & 1996 & 6.0 & 13.9 & 7.1 & 15.7 \\
\hline & 2000 & 9.0 & 18.3 & 12.2 & 18.1 \\
\hline & 2002 & 14.4 & 24.9 & 13.2 & 29.1 \\
\hline & 2006 & 11.8 & 21.5 & 11.8 & 24.2 \\
\hline & 2010 & 12.6 & 23.8 & 13.1 & 28.1 \\
\hline & 2012 & 16.7 & 32.8 & 18.2 & 36.2 \\
\hline & 2016 & 13.9 & 35.1 & 19.9 & 33.7 \\
\hline
\end{tabular}

Notes: Database from ALLBUS 1980-2016 (cumulative); only German respondents. Personal contact questions were not given a structured rhythm of inclusion in the ALLBUS questionnaire until 1996, when it was decided to collect the questions three times every decade (every $2 \mathrm{nd}$, 6th, and 10th year). Data was not collected in East Germany before reunification. 
Germans claiming to have had contact with immigrants at the workplace in 2016. Since the mid-1990s, there has also been a noticeable increase in contact in the family and neighborhood. In West Germany, it was reported in 1994 that $16.4 \%$ of respondents had contact in their family. In 2012, this number had jumped up to nearly $35 \%$. During that same time in East Germany, these numbers jumped from $4.6 \%$ to $16.7 \%$ respectively. It should be noted here that these numbers did sink slightly in 2016; however, this does not take away from the overall development of contact that occurred over the past three decades and does not diminish the predominantly unbounded growth in contact across all areas of life in West Germany.

The time series document a large social change in the life of the German population in the last decade. Not only has the composition of the society changed through migration, but also the everyday encounters with people from other nations has generally become normal. With such developments in contact between native Germans and foreigners, the question of how these contacts are perceived becomes essential to understanding the relationships between natives and foreigners in Germany. Once these relationships are better understood, the effects of such contact can be explored with regards to outgroup attitudes.

\section{Study 2}

\subsection{Data and Methods}

For this study, data from the GESIS Panel (GESIS, 2019b; Wagner et al., 2014), a probability-based mixed-mode access panel, was used to examine the existence and frequency of positive contact between autochthonous German respondents and foreigners and its effect on outgroup attitudes. While analyses of longitudinal intergroup contact processes for German participants with diverging migration backgrounds would have been especially desirable, the nature of the GESIS Panel, being a general population survey, did not allow such analyses, as the number of cases would have been too small for the presented study. That being said, data from 673 German respondents without migration background over four waves (Spring 2016, Autumn 2016, Spring 2017, and Autumn 2017) was used. In accordance with the work of Hamaker et al. (2015), a RI-CLPM was used alongside a CLPM in order to compare the results.

\subsection{Variables}

Two questions regarding the valuation of foreigners were selected: "How would you assess foreigners in Germany overall?" and "How would you describe your feelings towards foreigners in Germany in general?" Both questions used a five-point scale for answers, ranging from 1 "very negative," to 5 "very positive." Furthermore, two items were used that asked specifics on positive contact experiences with foreigners in Germany: "How frequently do you have positive or good contact with foreigners in your neighborhood?" and "How frequently do you have positive or good contact with refugees at your place of employment or apprenticeship?" A four-point scale was used for answering ( 1 "never," 2 "rarely," 3 "sometimes," and 4 "frequently"). It should be noted that the given dataset also included indicators of negative intergroup contact experiences in the said contexts. However, to increase comparability with the ALLBUS data, we only examined the effects of positive contact (as non-specified contact usually shows similar results as specifically positive contact does; Pettigrew \& Tropp, 2006).

\subsection{Results}

The descriptive statistics for the variables used in the analysis of the GESIS Panel are reported in Table 4 for all four waves of measurement. The attitudes and evaluations towards foreigners were relatively neutral in the Spring of 2016 (attitude: 3.12; overall evaluation: 3.15) and remain remarkably stable over the entire period. As previous research has found, those respondents that had neutral stances on foreigners in T1 recorded a relatively high stability in T4 (Schmidt et al., 2019). This high stability was also found among respondents that held negative views towards foreigners between T1 and T4, but not among those with positive stances at T1 (Schmidt et al., 2019). Positive contact experiences with foreigners also remained remarkably stable over time.

Table 4. Descriptive statistics on positive and negative intergroup contact and attitudes for foreigners for all four waves of the GESIS Panel. Source: GESIS (2019b).

\begin{tabular}{lcccccccc}
\hline & \multicolumn{2}{c}{ T1 } & \multicolumn{2}{c}{ T2 } & & T3 & & T4 \\
\hline Item & $\mathbf{M}$ & $\mathbf{s}^{\mathbf{2}}$ & $\mathbf{M}$ & $\mathbf{s}^{\mathbf{2}}$ & $\mathbf{M}$ & $\mathbf{s}^{\mathbf{2}}$ & $\mathbf{M}$ & $\mathbf{s}^{\mathbf{2}}$ \\
\hline Positive contact neighborhood & 2.41 & 1.05 & 2.35 & 1.12 & 2.48 & 1.07 & 2.47 & 0.99 \\
Positive contact workplace & 2.59 & 1.42 & 2.56 & 1.43 & 2.68 & 1.40 & 2.61 & 1.37 \\
Attitude & 3.12 & 0.59 & 3.15 & 0.44 & 3.11 & 0.48 & 3.07 & 0.46 \\
Overall evaluation & 3.15 & 0.59 & 3.13 & 0.46 & 3.07 & 0.46 & 3.07 & 0.43 \\
\hline
\end{tabular}

Notes: Database from GESIS Panel; German participants without migration background ( $N=673) . M=$ mean value, $\mathrm{s}^{2}=$ variance. Scale for contact experiences: 1 "never," 2 "rarely," 3 "sometimes," 4 "often"; scale for attitudes and evaluations: 1 "very negative," 2 "negative," 3 "neutral," 4 "positive," 5 "very positive." 
Based on these descriptive findings, a CLPM was analyzed to examine the effect of positive intergroup contact experiences on attitudes towards foreigners as well as reversed effects from attitudes to positive intergroup contact experiences in German adults (for all model specifications, please see model specifications of the baseline CLPM in the Annex). In this model, autoregressive paths (i.e., the influence of one construct at a previous wave of measurement on a later wave of measurement) as well as cross-lagged paths (i.e., the influence of one construct at a previous wave of measurement on another construct at a later wave of measurement) were included to ensure a causal interpretation of the effect of a predictor variable (e.g., intergroup contact) on a criterion variable (e.g., attitudes; Granger, 1969; Little, 2013).

All four waves of measurement available were used and the sample was defined as German participants without migration background to ensure that indeed intergroup contact was modelled. The measurement models contain latent variables measured by two indicators each for positive intergroup contact and attitudes (see Table 4). To ensure equal meaning of the latent variables over time, longitudinal metric measurement invariance (Little, 2013) was introduced, which did not substantially impair model fit (all model fit information can be found in Table A1 in the Annex). Additionally, restrictions of stationarity (i.e., longitudinal effects constrained to be equal over time; Cole \& Maxwell, 2003) were tested for, but could not be supported. As a consequence, we assume that the processes between the different waves of measurement vary substantially as a function of time and cannot be uniformly described.

The resulting model is displayed in Figure 1 as a simplified graph. It shows quite high stability coefficients for both intergroup contact and attitudes over time. This implies that, for example, Germans with a high level of positive intergroup contact experiences at one time point also show high levels of positive intergroup contact expe- riences in subsequent waves of measurement, and that participants with little positive intergroup contact experiences also have low rates of positive intergroup contact experiences at later waves. The respective standardized stability coefficients vary between .821 and .953 for positive intergroup contact, and between .762 and .849 for attitudes.

Surprisingly, and contrary to the literature, the crosslagged effects indicate that positive intergroup contact with foreigners predicts attitudes towards them at later waves only to a very small and non-significant extent, while simultaneously controlling for the stability of attitudes. The standardized cross-lagged effects vary between .016 and .069. Thus, we could find no empirical support for the contact hypothesis. The effect of attitudes predicting future positive contact effects over and above the stability of intergroup contact could equally not be observed. The standardized coefficients varied between .034 and .103. Adadis and Willoughby (2015) showed that effect sizes in panel studies are often much smaller than effect sizes in cross-sectional studies. Furthermore, they argued that the criteria for effect sizes for cross-sectional data should not be applied to panel data. The reason is that, in panel data, only the effect within the measured time period is grasped as the former state of the variables is controlled. Therefore, much lower effect sizes should be accepted if they were at least significant, which is not the case for the model at hand.

This surprising lack of cross-lagged effects might well be explained by the very high stability coefficients, which explain up to $90 \%$ of all observed variation and which literally leave very little variance in positive intergroup contact experiences and attitudes towards foreigners to be explained. The variance in attitudes was quite low to start with, as can be seen in Table 4. Another explanation might be the use of the quite indistinct outgroup description of "foreigners," which might refer to different nationalities, migration motives, and times of pres-

Model Fit: $\chi^{2}(92)=139.224, p=.001$; RMSEA: .028 [.018, .037], CFI: .989, SRMR: .39



Figure 1. Conventional CLPM for foreigners. Notes: Standardized regression coefficients are reported. The model is simplified and depicts only the structural relations of interest, omitting the underlying measurement model and covariations between constructs at the same timepoint. Significant paths are depicted darker. ${ }^{* * *} p<.001$. 
ence (Asbrock, Lemmer, Becker, Koller, \& Wagner, 2014; Schmidt et al., 2019).

Recently, CLPMs as described above have been criticized due to their inability to differentiate between within-person processes and between-person differences (Hamaker et al., 2015). This refers to the fact that longitudinal data demonstrate a hierarchical structure in which multiple waves of measurements are nested within the individual survey participants. Consequently, two sources of variation may partly or fully drive the effects produced by CLPMs: On the one hand, there might be differences between participants which are stable over time and thus introduce rank-order like differences between participants (e.g., influenced by personality traits, intergroup contact opportunity structure, intergroup ideologies, demographic characteristics). In the following, these effects will be referred to as betweenperson differences. On the other hand, participants might experience variation in positive and negative intergroup contact experiences and attitudes over time, and thus might situationally deviate from their usual level (i.e., the stable difference compared to other participants). For this reason, these deviations will be labelled within-person processes here.

Ignoring these different sources of variation in statistical models might lead to seriously biased results, as simulation studies and data re-analyses in other fields demonstrated (Hamaker et al., 2015; Kühnel \& Mays, 2018; Masselink et al., 2018). Additionally, exploring these differences appears to be quite relevant from a theoretical perspective: Though neither the original Allport text nor subsequent literature precisely defines whether the intergroup contact hypothesis refers to the within-person or between-person level, implicit assumptions, e.g., in intergroup contact interventions (Lemmer \& Wagner, 2015), refer to processes and changes hap- pening within individuals, i.e., within-person processes (Curran \& Bauer, 2011). Consequently, the CLPM is respecified as a RI-CLPM (Hamaker et al., 2015) to explore the impact of stable between-person differences and to identify which of the autoregressive and cross-lagged processes identified by the CLPM hold on a purely withinperson processes level. This model completely separates the observed variation in stable between-person difference factors (one per construct) and distinct timespecific situational within-person processes. The stability and cross-lagged coefficients that typically define a CLPM are specified on the level of within-person processes, and thus indicate only changes within individuals over time. The model specifications of longitudinal metric measurement invariance and non-stationarity described above still hold. Further information about the RI-CLPM can be found in Hamaker et al. (2015).

Figure 2 displays the effects of the RI-CLPM for foreigners. The conventional CLPM and the RI-CLPM are nested, and thus can be directly compared. This comparison indicated a substantially better model fit-and thus a better representation of the empirical variancecovariance-matrix-of the RI-CLPM (please see also Table $\mathrm{A} 1$ in the Annex). Thus, the RI-CLPM in Figure 2 should be preferred. The two green constructs on the left-hand side represent the between-person difference factors, which can be understood as stable rank-order differences between participants in positive intergroup contact experiences and attitudes over the entire measurement period. These latent constructs correlate with each other, whereby stable differences in positive intergroup contact experiences correlate positively but nonsignificantly with stable differences in attitudes. The direction of this effect corresponds to the theoretical predictions of the intergroup contact hypothesis. On the right-hand side, the blue-grey constructs describe the

Model Fit: $\chi^{2}(89)=78.837, p=.771 ;$ RMSEA: $.000[.000, .015]$, CFI: 1.000, SRMR: .035

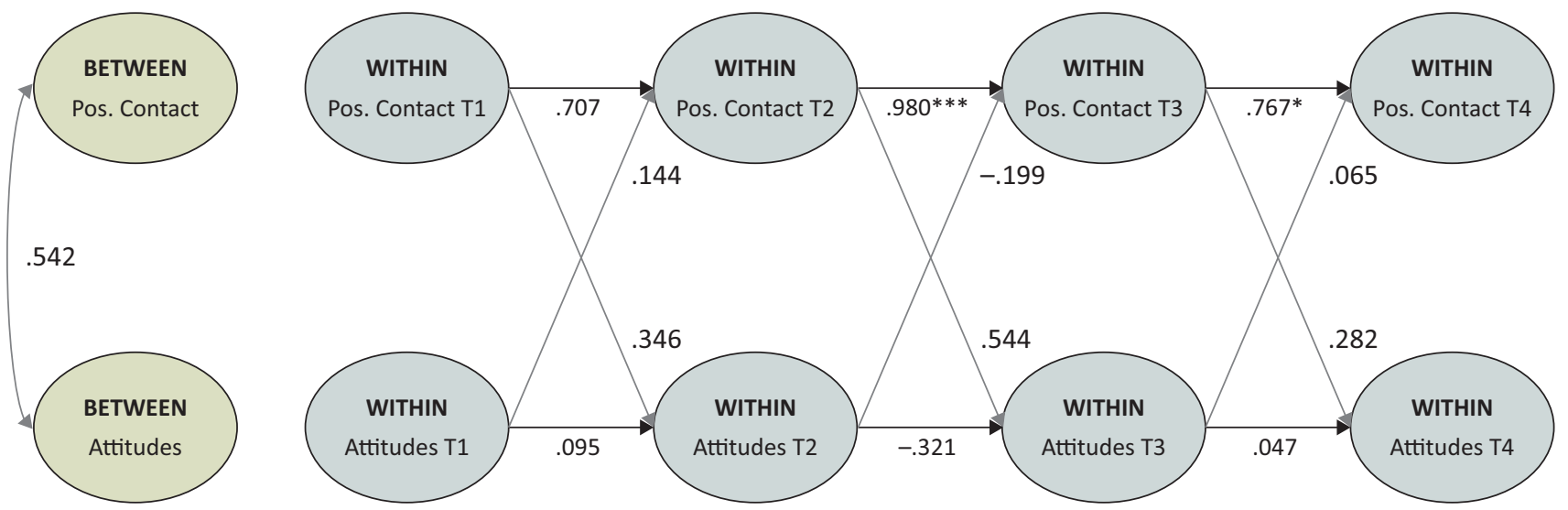

Figure 2. RI-CLPM for foreigners. Notes: Standardized regression coefficients are reported. The model is simplified and depicts only the structural relations of interest, omitting the underlying measurement model and covariations between constructs at the same timepoint. Green ellipses describe stable between-person differences, while blue-grey ellipses describe situational within-person processes. Significant paths are depicted darker. ${ }^{*} p<.05 ; * * * p<.001$. 
within-person processes over time and can be directly compared to the results displayed in Figure 1 . In the within-person model, most stability coefficients are reduced in their standardized coefficients and become nonsignificant. This applies to all stability coefficients of attitudes, and one stability coefficient of intergroup contact. The remainder of stability coefficients is not substantially changed. The same applies to the crosslagged coefficients, which remain non-significant and very small in size. These findings might be explained by the distribution of variance from the latent intergroup contact-and attitude factors into within-person and between-person variation. As indicated by the squared standardized factor loadings, for positive intergroup contact, more variance was allocated on the within-person level $(58.83 \%-62.73 \%)$ than on the between-person level (37.33\%-41.09\%). For attitudes towards foreigners, substantially more variance was given at the betweenperson level (56.55\%-80.64\%) than on the within-person level (19.36\%-43.43\%). This might be an indication of the role of stable characteristics, such as right-wing authoritarianism or social dominance orientation (Duckitt \& Sibley, 2010), in predicting outgroup attitudes.

\section{Conclusion}

The present article aimed at exploring the frequency and effect of intergroup contact between natives and migrants in Germany. This was done, on the one hand, through a descriptive analysis of intergroup contact frequencies as assessed by the ALLBUS data among those with various, if any, migrant background and the inherent East-West differences. On the other hand, this aim was achieved by depicting longitudinal intergroup contact processes of Germans with foreigners using four waves of the GESIS Panel. As has been evidenced, the increase in contact with foreigners living in Germany as well as the number of individuals with migrant background is an important aspect of modern research into immigration, integration, and outgroup attitudes. Further research should examine the intricacies of which micro-level factors predispose individuals to more positive contacts in the first place. This could be furthered by the examination of previous research to see if the usage of CLPMs has led to a misinterpretation of the contact/evaluation relationship.

The findings of both the conventional CLPM and the RI-CLPM are highly informative: Both fail to indicate any cross-lagged effect of positive intergroup contact on outgroup attitudes or vice versa. This finding might be due to the limited variation found in the GESIS Panel data. Nonetheless, it demonstrates the high importance of the examination of longitudinal data, which present a stricter test of the contact hypothesis and the underlying causality. Also, our findings give some indication that stable between-person differences might play an important role in explaining outgroup attitudes and intergroup contact.

\section{Acknowledgments}

The authors express their gratitude to the anonymous reviewers for their valuable comments on previous versions of this manuscript. They would also like to thank the Leibniz Association for funding this research. The publication of this article was funded by the Open Access Fund of the Leibniz Association.

\section{Conflict of Interests}

The authors declare no conflict of interests.

\section{References}

Adadis, P., \& Willoughby, T. (2015). Interpreting effect sizes when controlling for stability effects in longitudinal autoregressive models: Implications for psychological science. European Journal of Developmental Psychology, 12(1), 116-128.

Alba, R., Schmidt, P., \& Wasmer, M. (2003). Germans or foreigners? Attitudes toward ethnic minorities in post-reunification Germany. New York, NY: Palgrave Macmillan.

Allport, G. W. (1954). The nature of prejudice. Cambridge, MA: Addison-Wesley.

Asbrock, F., Lemmer, G., Becker, J. C., Koller, J., \& Wagner, U. (2014). "Who are these foreigners anyway?" The content of the term foreigner and its impact on prejudice. Sage Open, 4(2), 1-8. https://doi.org/10.1177/ 2158244014532819

Bundesamt für Migration und Flüchtlinge. (2019a). Aktuelle Zahlen zu Asyl, Ausgabe Juni 2019 [Current figures for asylum, June 2019 edition]. Nuremberg: Bundesamt für Migration und Flüchtlinge. Retrieved from https://www.bamf.de/SharedDocs/Anlagen/ DE/Statistik/AsylinZahlen/aktuelle-zahlen-juni2019.html;nn=282388

Bundesamt für Migration und Flüchtlinge. (2019b). Das Bundesamt in Zahlen 2018 [The Federal Office in numbers 2018]. Nuremberg: Bundesamt für Migration und Flüchtlinge. Retrieved from https:// www.bamf.de/SharedDocs/Anlagen/DE/Statistik/ BundesamtinZahlen/bundesamt-in-zahlen-2018. html;nn=284738

Coenders, M., \& Scheepers, P. (2008). Changes in resistance to the social integration of foreigners in Germany 1980-2000: Individual and contextual determinants. Journal of Ethnic and Migration Studies, 34(1), 1-26.

Cole, D. A., \& Maxwell, S. E. (2003). Testing meditational models with longitudinal data: Questions and tips in the use of structural equation modeling. Journal of Abnormal Psychology, 112(4), 558-577. https:// doi.org/10.1037/0021-843X.112.4.558

Curran, P. J., \& Bauer, D. J. (2011). The disaggregation of within-person and between-person effects in longitudinal models of change. Annual Review of Psychol- 
ogy, 62, 583-619. https://doi.org/10.1146/annurev. psych.093008.100356

Duckitt, J., \& Sibley, C. G. (2010). Personality, ideology, prejudice, and politics: A dual-process motivational model. Journal of Personality, 78(6), 1861-1894. https://doi.org/10.1111/j.1467-6494.2010.00672.x

GESIS. (2019a). German general social survey (ALLBUS)Cumulation 1980-2016 (Study No. ZA4588). Mannheim: GESIS. https://doi.org/10.4232/1.13291

GESIS. (2019b). GESIS Panel-Standard edition (Study No. ZA5665). Mannheim: GESIS. https://doi.org/ $10.4232 / 1.13377$

Göttsche, F. (2018). Bevölkerung mit Migrationshintergrund [Population with migration background]. In Statistisches Bundesamt \& Wissenschaftszentrum Berlin für Sozialforschung (Eds.), Datenreport 2018: Ein Sozialbericht für die Bundesrepublik Deutschland [Data report 2018: A social report for the Federal Republic of Germany] (pp. 28-42). Bonn: Bundeszentrale für politische Bildung.

Granger, C. W. J. (1969). Investigating causal relations by econometric models and cross-spectral methods. Econometrica, 37(3), 424-438.

Green, E. G., Visintin, E. P., \& Sarrasin, O. (2018). From ethnic group boundary demarcation to deprovincialization: The interplay of immigrant presence and ideological climate. International Journal of Comparative Sociology, 59(5/6), 383-402. https://doi.org/ $10.1177 / 0020715218801422$

Hadler, M., \& Flesken, A. (2018). Political rhetoric and attitudes toward nationhood: A time-comparative and cross-national analysis of 39 countries. International Journal of Comparative Sociology, 59(5/6), 362-382. https://doi.org/10.1177/0020715218810331

Hamaker, E., Kuiper, R. M., \& Grasman, R. (2015). A critique of the cross-lagged panel model. Psychological Methods, 20(1), 102-116.

Heath, A., Davidov, E., Ford, R., Green, E. G. T., Ramos, A., \& Schmidt, P. (2019). Contested terrain: Explaining divergent patterns of public opinion towards immigration within Europe. Journal of Ethnic and Migration Studies. Advance online publication. https://doi.org/ 10.1080/1369183X.2019.1550145

Jäckle, S., \& König, P. D. (2018). Threatening events and anti-refugee violence: An empirical analysis in the wake of the refugee crisis during the years 2015 and 2016 in Germany. European Sociological Review, 34(6), 728-743.

Koch, A., \& Wasmer, M. (2004). Der ALLBUS als Instrument zur Untersuchung sozialen Wandels: Eine Zwischenbilanz nach zwanzig Jahren [The ALLBUS as an instrument for the investigation of social change: An interim evaluation after 20 Years]. In R. Schmitt-Beck, M. Wasmer, \& A. Koch (Eds.), Sozialer und politischer Wandel in Deutschland [Social and political change in Germany] (pp. 13-42). Wiesbaden: Springer.

Kühnel, S., \& Leibold, J. (2000). Die anderen und wir: Das Verhältnis zwischen Deutschen und Aus- ländern aus der Sicht der in Deutschland lebenden Ausländer [The others and us: The relation between Germans and foreigners from the perspective of immigrants living in Germany]. In R. Alba, P. Schmidt, \& M. Wasmer (Eds.), Deutsche und Ausländer: Freunde, Fremde oder Feinde? Empirische Befunde und theoretische Erklärungen [Germans and foreigners: Friends, strangers, or enemies? Empirical findings and theoretical explanations] (pp. 111-146). Opladen: Westdeutscher Verlag.

Kühnel, S., \& Mays, A. (2018). Probleme von Cross-lagged Panelmodellen zur Analyse gegenseitiger Beeinflussung von Einstellung und Verhalten [Problems of cross-lagged panel models with the analysis of mutual interference from attitudes and behavior]. In J. Mayerl, T. Krause, A. Wahl, \& M. Wuketich (Eds.), Einstellungen und Verhalten in der empirischen Sozialforschung: Analytische Konzepte, Anwendungen und Analyseverfahren [Attitudes and behavior in empirical social research: Analytical concepts, applications, and analytical methods] (pp. 359-386). Heidelberg: Springer.

Lemmer, G., \& Wagner, U. (2015). Can we really reduce ethnic prejudice outside the lab? A meta-analysis of direct and indirect contact interventions. European Journal of Social Psychology, 45(2), 152-168. https:// doi.org/10.1002/ejsp.2079

Little, T. D. (2013). Longitudinal structural equation modeling. New York, NY: The Guilford Press.

Mallett, T. K., Wilson, T. D., \& Gilbert, D. T. (2008). Expect the unexpected: Failure to anticipate similarities leads to an intergroup forecasting error. Journal of Personality and Social Psychology, 94(2), 265-277.

Masselink, M., van Roekel, E., Hankin, B. L., Keijsers, L., Lodder, G. M. A., Vanhalst, J., . . . Oldehinkel, A. J. (2018). The longitudinal association between self-esteem and depressive symptoms in adolescents: Separating between-person effects from within-person effects. European Journal of Personality, 32(6), 653-671. https://doi.org/10.1002/per. 2179

Pettigrew, T. F., \& Tropp, L. R. (2006). Interpersonal relations and group processes: A meta-analytic test of intergroup contact theory. Journal of Personality and Social Psychology, 90(5), 751-783.

Pettigrew, T. F., Tropp, L. R., Wagner, U., \& Christ, O. (2011). Recent advances in intergroup contact theory. International Journal of Intercultural Relations, 35(3), 271-280.

Pfenning, U. (2019). Soziale Netzwerke: Zur NichtKarriere eines sozialrelevanten Konstrukts [Social networks: The non-career of a socially relevant construct]. In J. Mayerl, T. Krause, A. Wahl, \& M. Wuketch (Eds.), Einstellungen und Verhalten in der empirischen Sozialforschung: Analytische Konzepte, Anwendungen und Analyseverfahren [Attitudes and behavior in empirical social research: Analytical concepts, applications, and analytical methods] (pp. 
207-235). Wiesbaden: Springer.

Schmidt, P., \& Weick, S. (2017). Kontakte und die Wahrnehmung von Bedrohungen sind besonders wichtig für die Einschätzung von Migranten: Einstellungen der deutschen Bevölkerung zu Zuwandern von 1980 bis 2016 [Contacts and the perception of threats are particularly important for the evaluation of migrants: Positions of the German population towards immigrants from 1980-2016]. Informationsdienst Soziale Indikatoren, 57, 1-7.

Schmidt, P., Weick, S., \& Gloris, D. (2019). Wann wirken Kontakte zwischen Migranten und Mehrheitsgesellschaft? [When do contacts between migrants and the majority of society have an effect?]. Informationsdienst Soziale Indikatoren, 61, 24-29.

Sola, A. (2018). The 2015 refugee crisis in Germany: Concerns about immigration and populism (Paper 966). Berlin: DIW SOEP. Retrieved from https:// www.diw.de/documents/publikationen/73/diw_ 01.c.583437.de/diw_sp0966.pdf

Statistisches Bundesamt. (2019). Migration und Integration: Ausländische Bevölkerung nach Bundesländern und Jahren [Migration and integration: Foreign population by state and year]. Statistisches Bundesamt. Retrieved from https://www.destatis.de/ DE/Themen/Gesellschaft-Umwelt/Bevoelkerung/ Migration-Integration/Tabellen/auslaendischebevoelkerung-bundeslaender-jahre.html

United Nations High Commissioner for Refugees. (2016). Global trends: Forced displacement in 2015. Geneva: United Nations High Commissioner for Refugees. Retrieved from https://www.unhcr.org/ statistics/unhcrstats/576408cd7/unhcr-globaltrends-2015.html

Wagner, U., van Dick, R., Pettigrew, T. F., \& Christ, O. (2003). Ethnic prejudice in East and West Germany: The explanatory power of intergroup contact. Group Processes \& Intergroup Relations, 6(1), 22-36.

Wagner, U., Schmidt, P., \& Kauff, M. (2019). Attitudes towards ethnic minority groups. In GESIS (Ed.), GESIS panel study description (pp. 111-116). Mannheim: GESIS. Retrieved from https://dbk.gesis. org/dbksearch/download.asp?db=E\&id=52782

Williams, R. M., Jr. (1947). Reduction of intergroup tensions. New York, NY: Social Science Research Council.

\section{About the Authors}
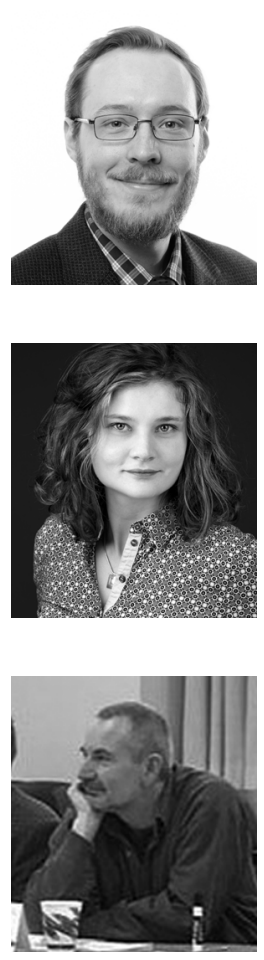

Bryan Bohrer is the Editorial Assistant for the Historical Social Research Journal and a Doctoral Researcher at GESIS-Leibniz Institute for the Social Sciences. His research interests include immigration studies, intergroup contact, political sociology, religious fundamentalism, and the sociology of religion. He plans to write his dissertation on the dimension of truth belief within religious fundamentalism and its relation to political voting behavior and authoritarianism in Europe.

Maria-Therese Friehs is pursuing her PhD on the topic of intergroup contact at Osnabrück University. Herein, she focuses on aspects of the measurement of intergroup contact as well as on the identification of within-person and between-person effects in longitudinal intergroup contact data. Her main research interests include the study of intergroup relations, with a focus on intergroup contact and stereotypes, and advanced data analysis.

Peter Schmidt is Professor Emeritus at the Department of Political Science and the Centre for Environment and Development (ZEU) at the University of Giessen. His main topics are applications of generalized latent variable models including structural equation models, reasoned action and rational choice models, values and explanation of national identity, and prejudice against minorities.

Stefan Weick studied Sociology at the University of Mannheim (Germany) and received his PhD from the University of Gießen. He is Senior Researcher at GESIS-Leibniz Institute for the Social Sciences. His research topics are quality of life research, income inequality, consumption, poverty, and migration studies. 
Annex

\section{Model Specifications of the Baseline CLPM}

- Latent constructs of positive intergroup contact and attitudes were modelled for all four waves separately using the two indicators described in Table 4 of the main text. For factor identification, factor loadings of the first items were fixed to 1.

- Two indicator-specific factors (one for positive intergroup contact, one for attitudes) were introduced for the items with the freely-estimated factor-loading in order to model the methods-specific variance created by the repeated application of the same items. These indicator-specific factors loaded only on the second item per construct in all four waves with a factor loading fixed to 1 . These factors were not allowed to covary with the substantial construct factors or with each other.

Table A1. Model fit indices of the (RI-)CLPM reported in 4.2.

\begin{tabular}{|c|c|c|c|c|c|c|c|c|c|c|}
\hline Model & AIC & $\chi^{2}$ & $\mathrm{df}$ & $p$ & RMSEA & $\mathrm{CFI}$ & SRMR & $\Delta \chi_{\mathrm{MLR}}^{2}$ & $\mathrm{df}$ & $p$ \\
\hline & \multicolumn{10}{|c|}{ GESIS Panel, Subsample "Refugees" } \\
\hline Baseline CLPM & 18630.201 & 135.412 & 86 & .0005 & .029 & .989 & .037 & / & / & / \\
\hline Metric MI & 18621.471 & 139.224 & 92 & .0011 & .028 & .989 & .039 & 3.357 & 6 & .763 \\
\hline Stability Stationarity & 18632.851 & 155.794 & 96 & .0001 & .030 & .987 & .051 & 14.380 & 4 & .006 \\
\hline RI-CLPM & 18561.923 & 78.837 & 89 & .7711 & .000 & 1.000 & .035 & 37.354 & 3 & $<.001$ \\
\hline
\end{tabular}

Notes: The MLR $\chi^{2}$ - difference test accounts for the impact of uni- and multivariate non-normality. The comparisons of the $\chi^{2}-$ difference test were as followed: Metric MI model vs. Baseline CLPM, Stability Stationarity vs. Baseline CLPM, and RI-CLPM vs. Metric MI model. 